\title{
A ciência do ser enquanto ser e o estudo da substância (Metafísica $\Gamma$ e Z)
}

\author{
Raphael Zillig (UFPR)
}

\begin{abstract}
Aristotle's Metaphysics introduces a science that purports to be universal in scope. Some problems concerning its constitution are dealt with in book $\Gamma$, where it is presented as a science of substance. In book $Z$ we find a study of substance that could be the research announced in $\Gamma$. Despite the evident convergence of the projects found in $\Gamma$ and $\mathrm{Z}$, a common reading of those books is rendered difficult by internal problems of both texts. The strategy presented in $\Gamma$ to establish the possibility of a universal science is unclear, and the doctrine of substance laid out in $\mathrm{Z}$ is notoriously affected by internal tensions. We propose to look for an understanding of "the science we are searching for" that could both clarify the strategy deployed in $\Gamma$ and solve the tensions of the concept of substance in $\mathrm{Z}$. With this aim in view, we suggest an account of that science on the basis of its characterization as a second-order science.
\end{abstract}

\section{Introdução}

A despeito dos grandes problemas de edição da Metafisica de Aristóteles, pode-se identificar nela o desenvolvimento da proposta de estabelecer uma ciência fundamental de grande generalidade. Uma vez que essa disciplina é identificada com o estudo do ser, sua constituição encontra uma dificuldade decorrente da notória tese aristotélica da não univocidade do ser. Se o ser é dito de muitos modos, como sustenta Aristóteles, não há uma ciência única que dela se ocupe. A solução é exposta no livro $\Gamma$ a partir da proposta da recondução do estudo do ser ao estudo da substância (ov่ $\sigma i ́ a)$, conceito que corresponde ao "ser primeiro e não um certo ser, mas ser sem mais" $\left(Z 1,1028^{a} 30-31\right)^{1}$.

Se não há dúvidas que, para Aristóteles, a prioridade da substância sobre os demais tipos de ser deve tornar possível a ciência proposta, o modo como isso ocorre está longe de ser claro. Para

\footnotetext{
${ }^{1}$ Todas as traduções dos textos de Aristóteles aqui citados são de minha autoria.
} 
Journal of Ancient Philosophy Vol. III 2009 Issue 1

compreender a relação entre o estudo do ser e o estudo da substância, seria natural recorrer ao livro $\mathrm{Z}$ da Metafísica, texto inteiramente dedicado a essa noção central ${ }^{2}$. O livro Z, afinal, iniciase exatamente com a mesma frase ("o ser se diz de muitos modos") que abre também $\Gamma 2$ e constitui o ponto de partida para a exposição da dificuldade de constituição da disciplina proposta por Aristóteles. Tal como anunciado em $\Gamma$, o livro $Z$ propõe desenvolver a ciência em constituição a partir da investigação acerca da substância (Z1, 1028 2 2-7). Ao que tudo indica, o livro $\mathrm{Z}$ executa o projeto defendido em $\Gamma^{3}$.

A sugestão de buscar apoio em $\mathrm{Z}$ para a compreensão da estratégia exposta em $\Gamma$, no entanto, esbarra contra o fato que a caracterização de substância oferecida em $Z$ está longe de ser livre de tensões. Há sobretudo um aparente impasse entre duas concepções discordantes de substância.

De acordo com uma das abordagens que o livro $\mathrm{Z}$ dá a esse conceito, a substância corresponde ao objeto de definição. A partir de outra abordagem, a substância parece ser identificada com o objeto sensível que existe de maneira independente. A tensão se instala porque o objeto genuíno de definição não pode conter matéria, ao passo que o objeto sensível existe unicamente como composto de matéria e forma (Z11 1037²5-33; Z15, 1039 20-31). Fica-se, ao fim da leitura de Z, sem saber se a substância corresponde a um objeto de definição abstrato ou não-material ou se ela corresponde ao ser composto de matéria e forma.

Essa tensão já foi tomada como uma hesitação que jamais é resolvida por Aristóteles (cf. Ross, 1924: v. I, p. xcii; v. II, p. 159-61) e a tentativa de desfazê-la produziu interpretações da noção de substância no livro $Z$ que diferem drasticamente entre si. Há leituras que procuram resguardar em $\mathrm{Z}$ o caráter substancial do objeto material, buscando torná-lo compatível com a

\footnotetext{
${ }^{2} \mathrm{O}$ estudo no qual se insere o livro $\mathrm{Z}$ (ao qual se pode adicionar o livro seguinte, $\mathrm{H}$ ), é posteriormente referido como tratado "sobre a substância e sobre o ser" (I 2, 1053 $\left.3^{\mathrm{b}} 17-18\right)$. Um modo semelhante de referir o mesmo estudo encontra-se também em $\Theta 1,1045^{\mathrm{b}} 27-28$.

${ }^{3}$ Tal afirmação, evidentemente, não está comprometida com a tese segundo a qual os livros $\mathrm{Z}$ e $\Gamma$ tenham sido originalmente redigidos como partes de um mesmo texto. A respeito dessa questão, ver Ross, 1924 : v. I, p. xviii-xxiv.
} 
Journal of Ancient Philosophy Vol. III 2009 Issue 1

abordagem que toma a substância como objeto de definição. Outras interpretações concluem que o objeto material, em $Z$, não pode ser tomado como substância em sentido estrito ${ }^{4}$.

A proposta a ser apresentada neste trabalho é a de buscar uma solução conjunta para os dois problemas. A partir de uma leitura comparativa entre $\Gamma$ e Z, pretende-se determinar com precisão a relação entre o estudo do ser e o estudo da substância que fica vaga em $\Gamma$ e compreender a tensão inerente à noção de substância em Z Isso deve ser feito a partir da proposta de um modelo para a compreensão da ciência do ser enquanto ser apresentada em $\Gamma$ que seja capaz de acomodar as duas caracterizações aparentemente discordantes da substância em $Z^{5}$. A compreensão da discussão a respeito da substância em $\mathrm{Z}$ à luz desse modelo deve, por seu turno, tornar mais clara a recondução do estudo do ser ao estudo da substância.

\footnotetext{
${ }^{4}$ A primeira posição pode ser ilustrada a partir da seguinte afirmação de Scaltsas: "A substância concreta não é dividida em dois componentes distintos, a saber, a matéria e a forma em atualidade, ou em instanciações de propriedades (universais ou tropos), vinculadas entre si por uma relação. A substância concreta é, antes, a forma em atualidade, tendo assimilado ao conjunto todos os demais componentes por reidentificação." (1994: p.5) Em contraste com essa posição que procura tomar o objeto material concreto como substância por meio de sua identificação com a forma em ato, a interpretação adversária acentua a distinção entre o objeto sensível e a forma. Veja-se, por exemplo, a seguinte afirmação de Morrison: "De acordo com o ponto de vista de Aristóteles, cada objeto material do senso comum deve a sua unidade e o seu ser a um único princípio imanente. Esse princípio imanente único é a causa do ser e unidade da ousia material. Ele, portanto, tem maior grau de ser e unidade do que a ousia material, sendo uma ousia anterior e merecendo em maior grau o título 'ousia'. Esse princípio imanente de ser e unidade é chamado por Aristóteles de to ti èn einai ou eidos, tradicionalmente traduzidos por 'essência' e 'forma'." (1996: p. 195$6)$.

${ }^{5}$ A relação bastante evidente entre o estabelecimento da possibilidade da ciência do ser que se apresenta em $\Gamma$ e a introdução do estudo da substância em Z1 é não raro mencionada pelos intérpretes (cf. Witt, 1989 : cap. 2; Loux, 1991 : p. 84; Bostock, 1994 : p. 45; Rapp, 1996 : p. 32-33). Não é comum, no entanto, que se procure desfazer a tensão central da noção de substância em $Z$ a partir de uma compreensão do seu papel na realização da ciência do ser enquanto ser (Irwin comenta as relações entre $\Gamma$ e o início de Z, mas a sua abordagem tende antes a ressaltar as diferenças entre as duas discussões; cf. 1988 : p. 199-200; cap. 10, n. 2). Na base desta proposta está a intuição segundo a qual é inútil examinar a tensão a partir do que as diferentes formulações têm de discordante (como faz Lesher, 1971), devendo-se, ao contrário, procurar o terreno comum no qual se desenvolvem as abordagens aparentemente divergentes da noção de substância.
} 
Journal of Ancient Philosophy Vol. III 2009 Issue 1

A ciência proposta

No primeiro livro da Metafísica, Aristóteles expõe o projeto de fundamentar uma disciplina universal denominada "sabedoria", que é apresentada como cume de uma escala formada por diferentes modos de apreender a realidade. Sensação, memória, experiência, arte, ciência e, finalmente, sabedoria, são dispostos em uma ordem que deve representar graus de conhecimento sucessivamente maiores $\left(\mathrm{A} 1,980^{\mathrm{a}} 27-82^{\mathrm{a}} 3\right)$.

Os diferentes patamares da escala não representam saltos meramente quantitativos com relação à posse de conhecimento, mas diferentes níveis de conhecimento. No primeiro patamar (a sensação), tem-se de um dado objeto uma apreensão que dura apenas enquanto o objeto estiver presente aos sentidos. No segundo patamar (a memória), essa apreensão é resguardada da fugacidade da mera sensação imediata. A partir da memória, os objetos percebidos pela sensação - e a própria sensação - podem ser compreendidos como itens que existem ao longo do tempo (cf. De Memoria 1, 449 24 -30). Assim, a memória não é superior à sensação por corresponder a um maior conhecimento do mesmo tipo, mas por tornar possível uma nova compreensão dos objetos e da faculdade da sensação.

Uma vez que a diferença de nível deve repetir-se na relação de cada termo da ordenação com seu predecessor, a sabedoria deve representar um salto de nível com relação às ciências em geral. Aristóteles trata a disciplina a ser fundamentada como uma ciência (ela é, de fato, a "ciência buscada": A2, 982ª), uma vez que ela, como as demais ciências, ocupa-se de princípios e causas $\left(\mathrm{A} 1,981^{\mathrm{b}} 25-82^{\mathrm{a}} 3\right)$. O seu tratamento dos princípios e causas, no entanto, deve ser de outro nível em relação ao tratamento das demais ciências. Com efeito, ela não trata de quaisquer princípios e causas, mas daqueles que, dentre eles, são primeiros (A1, 981 28-29), ou seja de princípios e causas que são anteriores aos das demais ciências. A sabedoria, assim, ocupa-se dos princípios que estão na base das demais ciências, correspondendo a uma ciência de segunda 
Journal of Ancient Philosophy Vol. III 2009 Issue 1

ordem. Ela não se ocupa de questões particulares a respeito deste ou daquele tipo de coisa, mas das condições gerais para que seja possível investigar qualquer tipo de coisa ${ }^{6}$.

Essa relação entre a ciência buscada e as demais ciências é evidente a partir da introdução do texto que mais diz a respeito da possibilidade e estruturação dessa nova disciplina, o livro $\Gamma$ da Metafisica:

Existe uma ciência que estuda o ser enquanto ser e o que se lhe atribui por si. Esta não é idêntica a nenhuma das ditas ciências particulares. Com efeito, nenhuma das outras ciências estuda universalmente a respeito do ser enquanto ser, mas tendo recortado uma parte dele, todas estudam os seus atributos, como, por exemplo, as ciências matemáticas. $\left(\Gamma 1,1003^{\text {a221- }}\right.$ 26)

A fórmula "ser enquanto ser" ( por oposição à limitação que, em cada ciência particular, demarca um objeto próprio de estudo. Qualquer uma das qualificações próprias das ciências particulares deve estar excluída do âmbito da ciência buscada. Seu objeto não corresponde ao ser enquanto é, por exemplo, mensurável ou móvel, mas meramente enquanto ser. Nessas condições, o escopo da ciência de segunda ordem resulta ser absolutamente universal e quem a domina deve "conhecer todas as coisas tanto quanto seja possível, sem ter conhecimento de cada coisa individualmente" (A2, 982 28 ), ou seja, deve conhecer as características que qualquer coisa possui unicamente na medida em que é (e não na medida em que é desta ou daquela natureza).

A universalidade da ciência buscada decorre do modo como o seu âmbito de investigação é estabelecido por oposição às delimitações das ciências particulares. Disso decorre igualmente o seu caráter estrutural ou "de segunda ordem". Se todas as ciências particulares têm um objeto de estudo delimitado, a ciência buscada estuda isso sobre o qual são dispostos os limites que demarcam o âmbito de cada ciência. Seu objeto é o que todas as ciências comuns devem pressupor como dado para que seja possível delimitar os objetos de suas investigações.

Por essa razão, os conceitos fundamentais dos quais se ocupa a ciência do ser enquanto ser são aqueles absolutamente gerais, os que não são estabelecidos a partir de qualquer delimitação.

\footnotetext{
${ }^{6}$ A caracterização da disciplina com a qual Aristóteles se ocupa na Metafisica como "ciência de segunda ordem" não é rara na literatura, podendo ser encontrada, por exemplo, em Irwin, 1988: p. 159-61 e Witt, 1989: p. 25-31.
} 
Journal of Ancient Philosophy Vol. III 2009 Issue 1

Além da própria noção de ser, estão no domínio dessa ciência as noções de um e o múltiplo. De fato, o um é dito de tantos modos quanto o ser, de maneira que a ciência que se ocupa de uma dessas noções deve ocupar-se também da outra $\left(\Gamma 2,1003^{\text {b }} 22-36\right)^{7}$. Já o múltiplo encontra-se sob essa ciência porque é oposto ao um e, como afirma Aristóteles, os opostos caem sob o escopo de uma mesma ciência $\left(\Gamma 2,1004^{\mathrm{a}} 9-22\right)$.

Essa pauta de estudos denuncia a herança platônica do projeto da ciência do ser enquanto ser. No horizonte da epistemologia de Platão há uma ciência universal ocupada, principalmente, das noções de ser e um. O modo como essas noções são concebidas, no entanto, determina o caráter da ciência universal. Aristóteles atribui aos platônicos as teses segundo as quais 1) ao ser e ao um não corresponde qualquer natureza subjacente distinta do ser e do um e 2) o ser e o um são substância de todos os seres (B4, 1001ª4-12; I 2, 1053 ${ }^{\mathrm{b}}$ 9-15). Ser e um são, assim, tomadas como noções objetivas, tal como os conceitos ordinários. A noção de "animal" não serve apenas para classificar os diferentes tipos de animais e ordenar as ciências que deles se ocupam, mas indica também uma natureza objetiva que é compartilhada por todos os animais. Do mesmo modo, as noções de ser e um, na perspectiva platônica, designam a realidade fundamental de todas as coisas.

Aristóteles recusa essa concepção das noções fundamentais da ciência do ser. Não há algo objetivo que se possa dizer do "um". Tudo o que é compreendido como "um" (e, por extensão, tudo o que é compreendido como "ser") é necessariamente compreendido segundo algum conceito distinto: "o um é uma certa natureza [diferente] em todo gênero e a natureza de coisa alguma é isso em si, a saber, o um" (I 2, 1054a-11; ver também Z4, 1030 10-12 e N1, 1087 33$88^{\mathrm{a} 14)}$.

Essa idéia pode ser identificada também na tese segundo a qual o ser (e, por extensão, o um) não é um gênero (B3, 998 22-27). "Ser" e "um" não designam a natureza de coisa alguma e em nenhum caso constituem respostas aceitáveis à pergunta "o que é?". As respostas mais gerais a esse respeito correspondem à enunciação dos diferentes "gêneros supremos" ou "categorias do ser" (quantidade, qualidade, relativo, etc.).

\footnotetext{
7 "O ser e o um são o mesmo, ou seja, uma única natureza, uma vez que se acompanham mutuamente."
} (Г2, $\left.1003^{\mathrm{b}} 22-24\right)$. Ver também: Z4, 1030 10 -12; I 2, 1053 ${ }^{\mathrm{b}} 25$; K3, $1061^{\mathrm{a}} 18$. 
Journal of Ancient Philosophy Vol. III 2009 Issue 1

Os gêneros supremos devem corresponder à máxima generalidade de tudo o que se pode dizer de objetivo a respeito das coisas. É expressão eloqüente dessa generalidade suprema o fato que, notoriamente, Aristóteles entenda que o termo "ser" sequer seja empregado com o mesmo sentido no domínio de cada gênero supremo ${ }^{8}$.

Em tais condições, é de se esperar que a ciência aristotélica do ser corresponda a um estudo de natureza particularmente formal, cujo objetivo não seria a enunciação de teses sobre o mundo, mas a exposição das condições de enunciação de teses objetivas. Efetivamente, muito do que Aristóteles faz no âmbito dessa ciência consiste em expor e estabelecer com rigor o que deve ser suposto pelas ciências comuns. Assim, é no âmbito dessa disciplina que Aristóteles desenvolve a defesa dos princípios mais gerais de todos $\left(\Gamma 3,1005^{\mathrm{a}} 19 \mathrm{-}^{\mathrm{b}} 2\right)$, aqueles sem os quais não pode haver discurso com sentido, a saber, os princípios de não-contradição e do terceiro excluído.

Com o mesmo intuito de estabelecer as condições de possibilidade da ciência em geral, logo após a defesa do princípio de não-contradição Aristóteles introduz a noção de "substância" (oủoía: $\Gamma 4,1007^{2} 20$ ). O papel dessa noção em $\Gamma 4$ é o de assegurar a satisfação de uma condição que não se limita ao discurso da ciência, valendo para qualquer enunciado que possa ser tomado como verdadeiro ou falso. Todo enunciado dessa natureza consiste na atribuição de algo a algo (Tì кaTá $T(\nu O S)^{9}$, do que se segue, trivialmente, como condição do discurso ao qual cabe verdade e falsidade, a existência de algo do qual se atribui algo.

Se a suposição desse algo que é sujeito de atribuição não é um mero expediente verbal, é necessário que nem todo sujeito de atribuição seja como o termo "músico", que pode não apenas ocorrer na posição de sujeito, mas também na de predicado (como em "Sócrates é músico"). Se esse fosse o caso, a cadeia de predicações regrediria ao infinito, de modo que toda resposta possível à pergunta "qual é o algo do qual se fala?" seria necessariamente tomada como uma proposição abreviada na qual estaria contida uma referência implícita a um sujeito anterior de

\footnotetext{
${ }^{8}$ A fórmula "o ser se diz de muitos modos" e suas correlatas estão entre as mais repetidas na Metafísica: A9, 992 $19 ; \Gamma 2,1003^{\mathrm{a}} 33 ; \Delta 11,1019^{\mathrm{a}} 4-5 ; \mathrm{E} 2,1026^{\mathrm{b}} 2 ; \mathrm{E} 4,1027^{\mathrm{b}} 31 ; 1028^{\mathrm{a}} 5 ; \mathrm{Z} 1,1028^{\mathrm{a}} 10 ; \mathrm{K} 3,1060^{\mathrm{b}} 32-33$; $\mathrm{K} 8,1064^{\mathrm{b}} 15 ; \mathrm{N} 2,1089^{\mathrm{a}} 7$.

${ }^{9}$ Cf. Da Interpretação 5, 17²1; 6, 17 25-6; Primeiros Analíticos I 1, $24^{\mathrm{a}} 16$.
} 
Journal of Ancient Philosophy Vol. III 2009 Issue 1

atribuição $\left(\Gamma 4,1007^{\mathrm{a} 33}-^{\mathrm{b}} 6\right)$. Nesse caso, qualquer tentativa de identificar isso do que se fala seria, na melhor das hipóteses, incompleta.

Para resolver a dificuldade, no entanto, não basta supor um termo que ocupe unicamente a posição de sujeito. Se não houver como determinar o significado desse termo, tampouco será possível fornecer uma resposta determinada à pergunta “do que se fala?”. É preciso, portanto, que

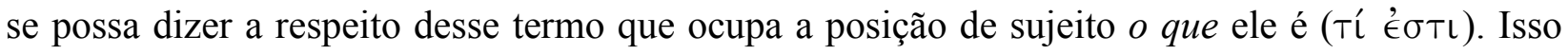
deve ser feito sem que se recaia no problema anterior, ou seja, o enunciado disso que é o primeiro sujeito de atribuição não pode apresentá-lo como sendo, ele próprio, dependente de um sujeito anterior. É preciso, portanto, que o enunciado do que é o primeiro sujeito de atribuição não inclua uma referência a algo distinto do próprio termo que deve ocupar a posição de sujeito.

Desse modo, deve haver uma distinção com respeito ao que se pode dizer de um sujeito. Ou bem uma atribuição afirma algo a respeito do sujeito, ou bem determina o que é o sujeito. $\mathrm{O}$ primeiro tipo de atribuição supõe um tipo de predicado que é sempre associado a um sujeito distinto dele próprio, ao passo que o segundo tipo supõe um predicado que significa algo que é, ele próprio, um sujeito.

Em $\Gamma 4$, como nos demais textos em que Aristóteles discute as condições segundo as quais o discurso não se preserva, essa distinção introduz a oposição entre substância (oư

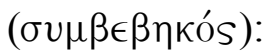

Significar a substância é significar que não é diferente o ser da própria coisa. (...) Com efeito, por meio disto distinguem-se a substância e o acidente: o branco ocorre como acidente ao homem porque [o homem] é branco, mas não porque é precisamente o que o branco é. Mas, se tudo é dito segundo acidente, não haverá nada primeiro ao qual se atribui, se o acidente significa sempre a predicação a um certo sujeito. $\left(\Gamma 4,1007^{\mathrm{a}} 25^{\mathrm{b}}{ }^{\mathrm{q}} 1\right)^{10}$

\footnotetext{
${ }^{10} \mathrm{O}$ mesmo modo de distinguir entre substância e acidente pode ser encontrado em Segundos Analíticos I $22,83^{\mathrm{a}} 24-30$. De fato, nesse texto, tanto quanto na passagem citada do livro $\Gamma$, o objetivo é mostrar a necessária determinação do sujeito primeiro. Em $\Gamma$, o problema é apresentado a partir da impossibilidade de se tomar todas as atribuições como sendo de natureza acidental. Nos Segundos Analíticos, Aristóteles pretende mostrar que uma cadeia de atribuições não pode proceder infinitamente "para baixo", ou seja, não pode ser o caso que, para toda atribuição do tipo " $a$ é $b$ ", haja um terceiro termo $c$ tal que $a$ seja atribuído como predicado a $c$ (cf. Seg. An. I 20,82a23ss.). Em ambos os casos o problema pode ser ilustrado a partir da sugestão segundo a qual todos os termos ocupando posição de sujeito fossem como o "músico".
} 
Journal of Ancient Philosophy Vol. III 2009 Issue 1

A noção de substância, portanto, é aqui introduzida como correspondendo a algo do qual se pode dizer precisamente o que ela é sem que seja necessário fazer referência a um sujeito diferente dele próprio.

Assim caracterizada, a suposição da noção de substância garante que tudo o que se diz é dito de algo determinado. No âmbito da fundamentação de uma ciência de segunda ordem, cabe mostrar que a inteligibilidade das demais ciências depende da suposição de algo determinado a respeito do qual se pode falar determinadamente. A física, por exemplo, não pode descrever o fenômeno da mudança sem atribuir a mudança a algo determinado. De mesmo modo, a geometria não pode perguntar se a soma dos ângulos internos de certa figura é igual a $180^{\circ}$ se não há algo determinado ao qual atribuir tal propriedade.

As noções de um, múltiplo, substância e não-contradição parecem encadear-se naturalmente na proposta de uma ciência formal de segunda ordem. Toda ciência deve respeitar o princípio de não-contradição e, portanto, deve aceitar que isso que é um não é outro, ou seja, deve aceitar a distinção entre um e múltiplo. A suposição de um sujeito determinado, por sua vez, é necessária para que, ao falar algo de algo, seja possível manter a distinção entre o um do qual se fala e o outro que se lhe atribui, evitando uma confusão entre o que é um e o que é múltiplo. Tudo permanece antes no domínio do discurso do que no da descrição da realidade.

\section{O conteúdo objetivo da ciência do ser enquanto ser}

Aristóteles, no entanto, parece entender que a sua ciência do ser não se limita a um estudo formal. É tarefa da filosofia e de nenhuma outra disciplina investigar se Sócrates e Sócrates sentado são o mesmo (Г2, $\left.1004^{\mathrm{b}} 1-4\right)$. Em outras palavras, a filosofia deve determinar se Sócrates e Sócrates sentado constituem uma unidade ou uma multiplicidade. Aristóteles, portanto, espera que a ciência do ser mostre em que condições dois itens hipoteticamente distintos o são de fato e em que condições eles formam uma unidade.

Supor que o um não é múltiplo e vice-versa é condição formal para discutir essa questão. Se quando se fala de Sócrates ou Sócrates sentado não se supõe serem distintos esses conceitos fundamentais, não há sequer como perguntar se ambos são o mesmo (isto é, um) ou diferentes 
Journal of Ancient Philosophy Vol. III 2009 Issue 1

(isto é, múltiplos). Isso, no entanto, está longe de ser suficiente para resolver a questão. Tanto a resposta que opta pela identidade entre Sócrates e Sócrates sentado, quanto a alternativa contrária podem ser apresentadas sem que os princípios fundamentais da significação e da coerência sejam lesados.

Agora, se resolver essa questão é tarefa da ciência buscada, então ela parece estar em conflito com os princípios que a afastaram da concepção da ciência do ser de Platão. Tomemos, por exemplo, a hipótese segundo a qual Sócrates e Sócrates sentado são o mesmo. Nesse caso, Sócrates e Sócrates sentado são fundamentalmente um. Ainda que se possa dizer que esta instância da ação de sentar-se seja um certo ser, podendo-se, portanto, dizer que ela é uma, é preciso aceitar que Sócrates é um em sentido mais fundamental. O um, portanto, está antes no gênero sob o qual está Sócrates e não no gênero sob o qual está o sentar-se. A decisão que Aristóteles quer encontrar na sua ciência do ser parece dotar um e ser de algum conteúdo objetivo.

Como pode isso ser possível em face da tese da dispersão do ser nos diversos gêneros supremos $^{11}$ ? Como se lê em K3, "se o ser é [dito] por homonímia e segundo nenhuma noção comum, ele não está sob uma ciência única, pois não há um gênero de tais coisas” (1060³3-35). Essa dificuldade não constitui empecilho apenas ao projeto platônico de uma ciência suprema, ocupada unicamente das noções mais universais de todas, aquelas de ser e um. A ciência aristotélica do ser enquanto ser também parece ser vulnerável a ela, se tal ciência não corresponde a um estudo meramente formal.

${ }^{11}$ Aristóteles concebe de diferentes modos a diversidade de sentidos do ser (cf. $\Delta 7, \mathrm{E} 2,1026^{\mathrm{a}} 33_{-}{ }^{\mathrm{b}} 2$ e $\Theta 10$, 1051 ${ }^{\mathrm{a} 34}$ - $^{\mathrm{b}} 2$ ). Além da diversidade referente às várias "categorias do ser", há, entre outras, aquelas resultantes das distinções entre ato e potência e entre verdadeiro e falso. Em $\Gamma 2$, principal texto a tratar do problema gerado pelos diversos sentidos de ser, Aristóteles não é explícito com relação a qual seja a diversidade relevante. Seria possível imaginar que o problema surge porque o ser é dito 1) segundo as categorias, 2) segundo ato e potência e 3) como verdadeiro. Pode-se, no entanto, inferir que, para Aristóteles, a ameaça ao projeto da ontologia surja, principalmente, da diversificação correspondente às categorias. Em primeiro lugar, elas são explicitamente mencionadas em Z1, 1028 $8^{\mathrm{a}} 10-20$, texto que, em certa medida, retoma a estratégia de $\Gamma 2$ para o resgate da proposta aristotélica da ciência do ser enquanto ser. Também é possível concluí-lo a partir do ataque ao platonismo em Ética a Nicômaco I 6, 1096a24-29 e Ética Eudêmia I 8, $1217^{\mathrm{b}} 19-18^{\mathrm{a}} 2$. Nesses dois últimos textos, o ataque é diretamente voltado à pretensão de estabelecer uma ciência única do bem, mas o argumento, nos dois casos, apela para o fato que o bem é dito segundo cada uma das categorias do ser. 
Journal of Ancient Philosophy Vol. III 2009 Issue 1

A solução (tão célebre quanto o problema) é exposta com uma brevidade algo excessiva em $\Gamma 2\left(1003^{\mathrm{a}} 33^{-}{ }^{\mathrm{b}} 19\right)$. Em linhas gerais, a estratégia consiste em identificar nos diferentes sentidos de "ser" um ponto comum que possa constituir objeto da ciência do ser.

Ainda que o ser se diga em diversas acepções, ele não corresponde a um homônimo completo ou por acidente. A atribuição de um termo homônimo completo a diferentes coisas não decorre de qualquer relação entre elas, sendo resultado dos acidentes históricos de um dado

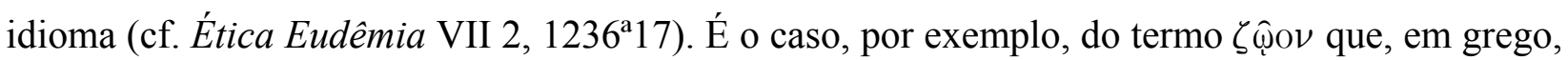
denomina o gênero animal, mas também um desenho qualquer (Categorias 1, 122-4). Se o ser fosse um termo dessa natureza, qualquer projeto de uma ciência única a seu respeito estaria condenado. Uma disciplina única do ser, nesse caso, seria semelhante a um estudo sobre os "bancos" que não considerasse as diferenças entre peças de mobiliário e instituições de crédito.

Diferentemente dos homônimos por acidente, é possível encontrar uma relação entre os vários significados de "ser". Dentre os muitos modos de dizer o "ser" há uma acepção primeira, por referência à qual todas as demais adquirem seus sentidos. Assim, mesmo que a atribuição de "ser" à substância e à quantidade não se dê por sinonímia (como no caso da atribuição de "animal" a homem e boi: Categ. 1, 1²-10), há uma relação entre ambas as atribuições, na medida em que a qualidade é qualidade de uma substância. O mesmo ocorre em cada categoria do ser, de maneira que "o ser é dito de muitos modos, mas por relação a um e a uma certa natureza e não por homonímia" ( $\left.\Gamma 2,1003^{\mathrm{b}} 33-34\right)$. Como, afirma Aristóteles, "em todos os casos, a ciência ocupa-se principalmente do que é primeiro, ou seja, do que as demais coisas dependem e a partir do qual são denominadas" ( $\left.\Gamma 2,1003^{\mathrm{b}} 16-17\right)$. A ciência do ser enquanto ser, portanto, corresponderá à ciência da substância ${ }^{12}$.

O conteúdo objetivo da ciência do ser, nesse caso, não se encontra diretamente na noção de ser, mas na de substância - que passa a ser tomada como ser em sentido primeiro. Note-se que

\footnotetext{
${ }^{12}$ Resta saber qual a natureza dessa recondução da ciência do ser ao estudo da substância. Owen (1960 : p.180) sugere que a recondução se dê pela redução ou tradução de afirmações sobre não-substâncias em afirmações sobre substâncias (proposta criticada por Leszl, 1970). A estratégia estaria baseada unicamente na dependência das definições de não-substâncias em relação às definições de substâncias. $\mathrm{O}$ apelo à noção de definição, no entanto, não parece suficiente. A definição do caminhar é anterior àquela do caminhante, ainda que o ser do caminhar dependa do ser de alguém que caminha (cf. M2, 1077 $36^{\mathrm{b}}{ }^{\mathrm{b}} 11$ ).
} 
Journal of Ancient Philosophy Vol. III 2009 Issue 1

isso impõe uma alteração significativa na caracterização de substância como conceito formal sugerida a partir de $\Gamma 4$. Se a ciência que Aristóteles procura fundamentar fosse de caráter estritamente formal, não haveria nada a dizer a respeito da substância para além do fato que ela constitui o sujeito último e determinado de atribuição. Se esse fosse o caso, seria possível identificar o que deve corresponder à substância de modo diferente a partir de cada ciência. A matemática provavelmente tomaria o ponto como substância em maior grau do que a linha e o plano, ao passo que a física talvez indicasse os elementos água, ar, terra e fogo como substâncias. Uma ciência de segunda ordem que fosse unicamente formal não encontraria qualquer conflito na coexistência dessas duas posições. O fato que a conjunção das duas é tomada por Aristóteles como uma aporia que deve ser desfeita para que o projeto em desenvolvimento na Metafísica avance (B5, 1001 $\left.26-2^{\mathrm{a}} 20\right)$ mostra também que ele não concebe desse modo a sua ciência de segunda ordem.

\section{A ciência da substância}

Tendo concluído que a noção de substância não deve ser de natureza meramente formal, resta identificar o modo pelo qual é determinado o seu conteúdo. Para tanto, convém notar que as questões a respeito do que deve contar como um em sentido fundamental não se aplicam unicamente a itens abstratos ou a seres não-sensíveis. Ao contrário, é no âmbito dos seres sensíveis e submetidos à mudança que se encontram os problemas ao mesmo tempo mais importantes e mais difíceis com relação a unidade e multiplicidade. A existência dos seres sensíveis é naturalmente descrita a partir das noções de unidade e multiplicidade: Aristóteles entende que o repouso pertence ao um, ao passo que a mudança pertence ao múltiplo ( $\Gamma 2$, 1004 29). Não é fácil, no entanto, delimitar o emprego de cada uma dessas noções no domínio do sensível. Os seres sensíveis estão em contínua mudança, de modo que há neles muito do indeterminado $\left(\Gamma 5,1010^{\mathrm{a}} 3\right)$. A indeterminação é tamanha, que alguns filósofos acreditaram ser necessário abrir mão do princípio de não-contradição para tratar dos seres sensíveis $\left(\Gamma 4,1005^{\mathrm{b}} 35\right.$ $1006^{\mathrm{a}} 3 ; \Gamma 5,1009^{\mathrm{a} 22-30) .}$ 
Journal of Ancient Philosophy Vol. III 2009 Issue 1

Se a indeterminação do ser sensível é capaz até mesmo de induzir "os que mais procuram e amam a verdade" $\left(\Gamma 5,1009^{\mathrm{b}} 33-38\right)$ a abandonar um princípio sem o qual não é sequer possível distinguir o um do múltiplo, então é no âmbito desse ser que se deve estabelecer as bases de toda a ciência. De nada adianta estabelecer abstratamente os princípios gerais da inteligibilidade, se a mera experiência ordinária do mundo sensível é capaz de por tudo a perder ${ }^{13}$. As bases da ciência geral que se ocupa de tudo o que é apenas suposto pelas demais ciências não podem parecer frágeis quando examinadas a partir do ponto de vista de uma ciência de primeira ordem como a física. Assim, se os princípios mais fundamentais da razão e do discurso parecem dever ser abandonados quando se estuda os seres sensíveis, é precisamente nesse âmbito que se faz necessário estabelecer os fundamentos da ciência do ser.

Agora, como determinar o que deve contar como "um" no mundo sensível? Evidentemente, não há meio a priori de decidir a questão, do modo como Aristóteles, por exemplo, estabelece em Г4 que não se pode duvidar do princípio de não-contradição. Um evento como Sócrates sentando-se pode ser descrito sem contradição como correspondendo a uma alteração de um único ser que permanece idêntico a si próprio ao longo do processo, como o surgimento de um novo ser (Sócrates-sentado) ou como a associação de dois seres distintos (Sócrates e o sentar-se). Não há como escolher qualquer uma das alternativas sem levar em consideração questões de natureza empírica. Em última análise, a escolha de uma das respostas alternativas depende da sua capacidade de explicar as regularidades do mundo sensível. Se, por exemplo, a geração do ser Sócrates-sentado fosse mais explicativa do que a continuidade de um mesmo sujeito que adquire uma propriedade, essa seria a alternativa escolhida ${ }^{14}$. O que é substância, portanto, deve ser determinado a partir de um critério empírico-explicativo.

A ciência do ser enquanto ser, portanto, possui dois aspectos. Um deles é de natureza estritamente formal, ao passo que o outro não se realiza sem a abordagem de questões de natureza

\footnotetext{
${ }^{13}$ A obsessão pelos raciocínios excessivamente abstratos é característica dos platônicos e causa de muitos dos seus equívocos $\left(\mathrm{A} 6,987 \mathrm{~b} 29-31 ; \Lambda 1,1096^{\mathrm{a} 27-28}\right.$; M8, 1084 $\left.23-25 ; \mathrm{N} 1,1087^{\mathrm{b}} 18-21\right)$.

${ }^{14}$ Aos olhos de Aristóteles, uma das maiores falhas da teoria das Idéias é a sua incapacidade de prover explicações para os eventos do mundo sensível (A9, 991 $\left.{ }^{\mathrm{a}} 9-11 / \mathrm{M} 5,1079^{\mathrm{b}} 12-15 ; \mathrm{Z} 8,1033^{\mathrm{b}} 26-28\right)$.
} 
Journal of Ancient Philosophy Vol. III 2009 Issue 1

empírica ${ }^{15}$. Cabe notar que a existência desse segundo aspecto não reduz a ciência buscada à física nem a transforma em um estudo de primeira ordem. As escolhas que, no âmbito dessa ciência, devem ser feitas com bases empíricas incluem-se na proposta da estruturação do conhecimento científico em geral, ainda que não do mesmo modo que as teses formais. Não se trata mais, como no caso da prova do princípio de não-contradição, de expor uma estrutura lógica que deve ser suposta para a enunciação de qualquer hipótese científica, mas de apresentar uma concepção geral de mundo que, sendo compartilhada por todas as disciplinas científicas, deve dotar a ciência como um todo de máxima coerência e capacidade de explicação.

\section{O livro Z}

De acordo com a interpretação aqui apresentada para a ciência do ser enquanto ser, a compreensão da noção de substância é desenvolvida a partir de uma base formal que é complementada por um conteúdo objetivo de ordem empírico-explicativa. Se o livro Z, como parece indicar a sua primeira seção, desenvolve o estudo da substância que é anunciado em $\Gamma$, é de se esperar nele estejam contemplados esses dois aspectos. De fato, é possível distinguir em Z duas abordagens da substância, correspondendo cada uma a um dos aspectos identificados na ciência apresentada em $\Gamma$.

A abordagem formal da substância é, não apenas, mas principalmente desenvolvida em Z46. Nessas seções não ocorrem as noções de matéria e forma, que são originárias da física e estão necessariamente vinculadas à compreensão empírica do mundo sensível. A argumentação desenvolvida nesses textos pode ser tomada como refinamento da discussão formal de $\Gamma 4$ e Segundos Analíticos I 22 a respeito das condições de determinação do sujeito do qual se fala. Nos Segundos Analíticos, "as coisas que significam a substância” referem-se de um modo geral à resposta à pergunta "o que é?", quando aplicada ao sujeito primeiro de atribuição. A partir dessa caracterização é possível tomar "animal" como a substância do homem. De fato, "animal” não inclui em si nada externo ao próprio homem, de modo que a distinção entre substância e acidente

\footnotetext{
${ }^{15}$ Descrições da ciência do ser enquanto ser que nela identificam uma distinção de dois aspectos definidos de modo semelhante ao que é apresentado aqui podem ser encontrados em Irwin (1988) e Code (1997).
} 
Journal of Ancient Philosophy Vol. III 2009 Issue 1

é respeitada. No entanto, "animal" não corresponde a uma caracterização suficientemente determinada do que é o sujeito primeiro. Um animal pode ser um homem, um cavalo ou peixe. Ainda que "animal" seja uma resposta correta à pergunta "o que é?" quando feita diante de Sócrates, ela é certamente uma resposta insuficiente.

Para delimitar com maior precisão as condições de determinação do sujeito de atribuição,

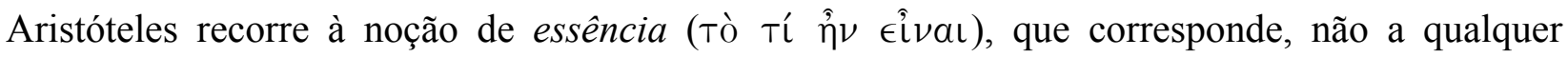
resposta à pergunta “o que é?", mas à resposta completa e precisa a essa questão ${ }^{16}$.

Aristóteles delimita a noção de essência eliminando progressivamente toda vagueza ou indeterminação da resposta à pergunta "o que é?" ". "Animal" não pode ser a essência de coisa alguma devido à sua indeterminação ${ }^{18}$. À espécie desse gênero, por sua vez, pode-se atribuir uma essência, uma vez que a diferença específica seleciona apenas uma das possibilidades do gênero, eliminando toda a indeterminação. "Animal racional" designa unicamente a espécie humana, que é, então, considerada à parte de todos os demais animais. Desse modo, o paradigma do que tem essência torna-se a "espécie de gênero" (Z4, 1030¹1-13), ou seja, o resultado da delimitação do gênero por uma diferença específica. Ter essência, nessa perspectiva, corresponde a ser perfeitamente definível.

Se a essência determina o que é o sujeito último do qual se fala e este é compreendido como substância, tem-se que apenas algo definível segundo o critério preciso desenvolvido em Z4 pode ser tomado como substância (Z6, 1032a4-6). Sem pretender determinar com precisão que tipo de

\footnotetext{
${ }^{16}$ Em um estudo clássico, Curt Arpe comenta (1938: p. 8-11) que, na formação do vocabulário técnico a partir de Sócrates, a expressão Tí é $\sigma \tau \iota$ do grego ordinário passa a designar não apenas a pergunta "o que é?", mas também a sua resposta, significando, então, isso que a coisa, nela mesma, é. Esse sentido técnico, contudo, jamais teria perdido completamente a imprecisão do idioma ordinário. O Tí éotı pode corresponder à definição completa de algo, à definição parcial (a indicação do gênero, por exemplo) ou

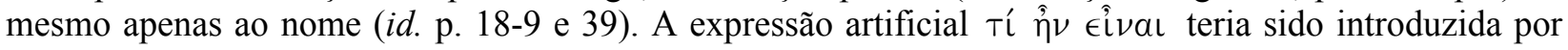
Aristóteles para evitar essa imprecisão, significando exclusivamente a definição completa ou essência de algo.

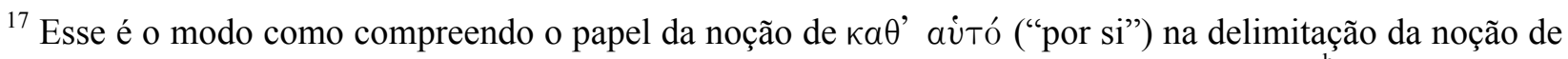
essência em Z4. A partir de uma identificação inicial da essência com o "por si" (1029b14), Aristóteles estabelece o tipo especifico de "ser por si" que deve corresponder à essência.

${ }^{18}$ Esse modo de compreender o resultado da delimitação da noção de essência corresponde a um modo peculiar de interpretar a delimitação operada sobre o conceito de "por si" (cf. Bostock, 1994: p. 87).
} 
Journal of Ancient Philosophy Vol. III 2009 Issue 1

coisa satisfaz essa caracterização formal da substância, cabe notar que ela não favorece a compreensão dos seres sensíveis como substâncias. Os seres sensíveis são constituídos a partir matéria e são, portanto, em certa medida indeterminados. Tal como o gênero animal, o homem de carne e ossos guarda uma certa indeterminação. Se "animal" é indeterminado por poder corresponder a cavalo, peixe ou homem, as porções de carne e osso que constituem o corpo dado homem são, em si mesmas, indeterminadas na mesma medida. Dispostas de modo diferente, as mesmas porções de matéria que formam o corpo de Sócrates poderiam formar um corpo de peixe ou cavalo. Seres como o homem e o cavalo particulares não parecem satisfazer as condições requeridas para que algo tenha uma definição em sentido estrito e uma essência (Z11 1037²5-33; Z15, 1039 ${ }^{\mathrm{b}} 20-31$, ver também Z7, 1032 ${ }^{\mathrm{b}} 14$ ).

No entanto, é bastante claro, em Z, que o termo "substância" deve poder ser aplicado a certos seres sensíveis. Até mesmo nas passagens recém citadas, nas quais se afirma que, existindo em composição com a matéria, um item não pode ser definido, o termo substância é atribuído a itens sensíveis e materiais. Além disso, muito do que Aristóteles afirma em Z sobre a substância diz respeito inegavelmente à explicação de questões empíricas. Particularmente característica é a discussão de Z7-9 a respeito da geração dos seres sensíveis. Também pode ser compreendida segundo esse viés a discussão de Z17 a respeito de como a forma é capaz de explicar que tal porção de matéria torna-se tal composto. De um modo geral, pode-se dizer que esses capítulos buscam estabelecer princípios que devem tornar compreensíveis as regularidades do mundo sensível ${ }^{19}$.

Essa discussão concorre para uma caracterização da noção de substância, que não permanece limitada à discussão formal. Está em questão a identificação dos seres que, tendo sido tomados como substâncias (ou seja, como seres dos quais se pode dizer que são "um" em sentido primeiro), tornam coerente a realidade sensível. Esse foco de interesse está presente no livro Z

\footnotetext{
${ }^{19}$ Como exemplos de tais princípios explicativos do mundo sensível expostos nesses capítulos pode-se citar os seguintes: "tudo o que vem a ser, vem a ser por efeito de algo, vem a ser a partir de algo e vem a ser algo" (Z7, 1032 13-14); isso a partir de que algo vem a ser não sofre processo de geração (Z8,

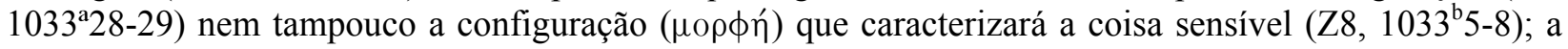
disposição pela qual estão conjugados certos elementos não é, ela própria, um elemento da mesma natureza, mas é a causa de tal composição $\left(Z 17,1041^{\mathrm{b}} 11-27\right)$.
} 
Journal of Ancient Philosophy Vol. III 2009 Issue 1

desde Z2, quando se apresenta um conjunto de hipóteses a respeito do que deve contar como substância. As Idéias platônicas são candidatos rejeitados por não contribuírem em nada para a compreensão do vir a ser das coisas sensíveis $\left(Z 8,1033^{\mathrm{b}} 26-29\right)$. Outras propostas, como as partes dos seres vivos e os elementos, são igualmente recusadas ao longo da discussão $\left(Z 16,1040^{\mathrm{b}} 5\right.$ 10).

Agora, como lidar com a discrepância entre o que exige o desenvolvimento da concepção formal de substância e o que pode ser tomado como substância segundo o critério empíricoexplicativo? Mesmo que, entre as coisas sensíveis, seja possível identificar um certo tipo de ser cuja relativa constância e regularidade permita entender o mundo mutável segundo alguma determinação, tal ser não poderá satisfazer os requisitos formais de Z4-6.

Em primeiro lugar, cabe notar que se pode tomar a discussão formal como apresentação de um ideal de substância elaborado a partir de uma concepção rigorosa de conhecimento. Do fato que não se pode ter conhecimento das coisas sensíveis nessa medida não se segue que delas não se possa ter conhecimento genuíno. O modelo ideal, assim, indica a direção a seguir e a contraparte empírica, desenvolvendo-se na direção indicada, deve mostrar o quanto se pode conhecer as coisas. A substância sensível, em última análise, será o que for capaz de explicar os eventos do mundo mutável realizando na maior medida possível o ideal estabelecido a partir da argumentação formal.

O caminho (que aqui será apenas indicado) para identificar que tipo de ser satisfaz na maior medida possível esse ideal de conhecimento está na contribuição do viés teleológico ao modelo de substância formulado. Em Z17, Aristóteles introduz a compreensão da essência como causa. Isso pode ser compreendido a partir do fato que, no caso das substâncias sensíveis, a essência, tal como expressa pela definição, deve orientar o vir a ser e a existência do ser sensível. Sócrates nunca corresponde perfeitamente à essência do ser humano, mas a sua existência pode ser explicada a partir da busca pela realização dessa essência, que é tomada como fim.

Esse fato permite estabelecer uma diferença fundamental entre seres como Sócrates e Bucéfalo e seres como este branco. A essência expressa pela definição do branco permite identificar instâncias dessa cor, mas não é possível explicar as etapas da geração desse item tomando a essência da cor como fim. Ao contrário, a geração e a continuidade da existência de 
Journal of Ancient Philosophy Vol. III 2009 Issue 1

tais seres explicam-se antes a partir da realização da essência do ser que serve como substrato para tais itens. $O$ branco existe sempre necessariamente em uma superfície, que pode corresponder, por exemplo, a madeira ou pele. A geração e existência do branco sobre a madeira ou sobre a pele será explicada de modo diferente em cada um dos casos. Em última análise, tal explicação deverá apelar para propriedades do tipo característico de superfície em questão, as quais são explicáveis a partir da compreensão da superfície como parte constituinte de um ser como um animal ou uma planta particular. Em outras palavras, o modelo teleológico que explica a constituição de animais e plantas particulares a partir da sua essência compreendida como fim deve estar na base da explicação da existência de seres como o branco. Tem-se, com isso, um critério de distinção entre seres substanciais e não-substanciais e um modo de compreender como o estudo da substância pode ser prioritário em relação ao estudo dos demais seres.

\section{Referências bibliográficas}

Bywater, I. Aristotelis Ethica Nicomachea. Oxford, Clarendon, 1894.

Minio-Paluello, L. (ed.). Aristotelis Categoriae et Liber De Interpretatione. Oxford, Clarendon, 1949.

Ross, W. D. Aristotle's Metaphysics - a revised text with introduction and commentary by W. D. Ross. Oxford, Clarendon, 1924.

. Aristotle's Prior and Posterior Analytics - a revised text with introduction and commentary by W. D. Ross. Oxford, Clarendon, 1949.

. Aristotle: Parva Naturalia - a revised text with introduction and commentary. Oxford, Clarendon, 1955.

Walzer, R. R.; Mingay, J. M. Aristotelis Ethica Eudemia. Oxford, Clarendon, 1991.

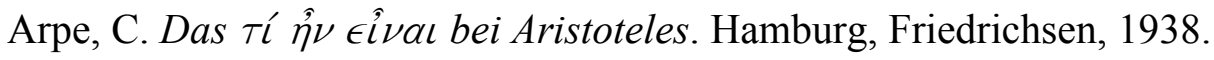

Bostock, D. Metaphysics. Books $Z$ and $H$ - translated with a commentary by David Bostock. Oxford, Clarendon Press, 1994.

Code, A. "Aristotle's metaphysics as a science of principles". Revue internationale de philosophie vol. 3, n. 201, 1997, p. 357-78. 
Journal of Ancient Philosophy Vol. III 2009 Issue 1

Irwin, T. Aristotle's first principles. Oxford, Clarendon, 1988.

Lesher, J. H. "Aristotle on form, substance and universals: a dilemma". Phronesis 16, 1971, p. $169-78$.

Leszl, W. Logic and metaphysics in Aristotle. Padova, Antenore, 1970.

Loux, M. J. Primary Ousia - an essay on Aristotle's Metaphysics $Z$ and H. Ithaca, Cornell University Press, 1991.

Morrison, D. "Substance as cause (Z 17)". In: Rapp, C. Metaphysik - Die Substanzbücher (Z, H, $\Theta)$, Berlin, Akademie Verlag, 1996.

Owen, G. E. L. "Logic and metaphysics in some earlier works of Aristotle". In: Düring, I., Owen, G. E. L. Aristotle and Plato in the mid-fourth century. Göteborg, Elanders Boktryckeri Aktiebolag, 1960.

Rapp, C. "Substanz als vorrangig Seiendes (Z1)". In: . Metaphysik, die Substanzbücher (Z, $H, \Theta)$, Berlin, Akademie Verlag, 1996, p. 27-40.

Scaltsas, T. Substance and Universal in Aristotle's Metaphysics. Ithaca, Cornell University Press, 1994.

Witt, C. Substance and essence in Aristotle - an interpretation of Metaphysics VII-IX. Ithaca. Cornell University Press, 1989. 